\title{
Increased haemodynamic adrenergic load with isoflurane anaesthesia in type 2 diabetic and obese rats in vivo
}

\author{
Carol T Bussey*, Anne E de Leeuw and Regis R Lamberts
}

\begin{abstract}
Background: Increasing numbers of type 2 diabetic and obese patients with enhanced rates of cardiovascular complications require surgical interventions, however they have a higher incidence of perioperative haemodynamic complications, which has been linked to adrenergic dysfunction. Therefore, we aimed to determine how $a-$ and $\beta$-adrenoceptor (AR)-mediated haemodynamic responses are affected by isoflurane anaesthesia in experimental type 2 diabetes and obesity in vivo.
\end{abstract}

Methods: Sixteen-week old male Zucker type 2 Diabetic Fatty (ZDF) rats, Zucker Obese rats and their lean counterparts ( $n=7-9$ per group) were instrumented with radio telemeters to record blood pressure and heart rate and with vascular access ports for non-invasive intravenous drug delivery in vivo. Haemodynamic effects of a-AR (phenylephrine; 1-100 $\mathrm{gg}_{\mathrm{kg}}{ }^{-1}$ ) or $\beta$-AR (dobutamine; 2-120 $\mu \mathrm{g} \cdot \mathrm{kg}^{-1}$ ) stimulation were assessed under conscious and anaesthetised (isoflurane; $2 \%$ ) conditions.

Results: Vascular a-AR sensitivity was increased in both diabetic (non-diabetic $80 \pm 3$ vs. diabetic $95 \pm 4 \Delta \mathrm{mmHg}$ at $100 \mu \mathrm{g} . \mathrm{kg}^{-1} ; p<0.05$ ) and obese (lean $65 \pm 6$ vs. obese $84 \pm 6 \Delta \mathrm{mmHg}$ at $20 \mu \mathrm{g} . \mathrm{kg}^{-1} ; p<0.05$ ) conscious rats. Interestingly, anaesthesia exacerbated and prolonged the increased a-AR function in both diabetic and obese animals (non-diabetic $51 \pm 1$ vs. diabetic $68 \pm 4 \Delta \mathrm{mmHg}$, lean $61 \pm 5$ vs. obese $84 \pm 2 \Delta \mathrm{mmHg}$ at $20 \mu \mathrm{gg}^{-1} \mathrm{~kg}^{-1}$; $p<0.05$ ). Meanwhile, $\beta$-AR chronotropic sensitivity was reduced in conscious diabetic and obese rats (non-diabetic $58 \pm 7$ vs. diabetic $27 \pm 8 \Delta$ bpm, lean $103 \pm 12$ vs. obese $61 \pm 9 \Delta$ bpm at $15 \mu \mathrm{g} . \mathrm{kg}^{-1} ; p<0.05$ ). Anaesthesia normalised chronotropic $\beta$-AR responses, via either a limited reduction in obese (lean $51 \pm 3$ vs. obese $66 \pm 5 \Delta \mathrm{bpm}$; NS at $15 \mu \mathrm{g} . \mathrm{kg}^{-1}$ ) or increased responses in diabetic animals (non-diabetic $49 \pm 8$ vs. diabetic $63 \pm 8 \Delta \mathrm{bpm}$, at $15 \mu \mathrm{g} . \mathrm{kg}^{-1}$; NS at $15 \mu \mathrm{g} \cdot \mathrm{kg}^{-1}$ ).

Conclusions: Long term metabolic stress, such as during type 2 diabetes and obesity, alters $a$ - and $\beta$-AR function, its dynamics and the interaction with isoflurane anaesthesia. During anaesthesia, enhanced a-AR sensitivity and normalised $\beta$-AR function may impair cardiovascular function in experimental type 2 diabetes and obesity.

Keywords: Anaesthesia, Conscious, Haemodynamic, Type 2 diabetes, Obesity, in vivo

\footnotetext{
* Correspondence: carol.bussey@otago.ac.nz

HeartOtago, Department of Physiology, Otago School of Medical Sciences,

University of Otago, PO Box 56, Dunedin 9054, New Zealand
} 


\section{Background}

The rapid expansion of the type 2 diabetes and obesity co-epidemics impacts heavily on cardiovascular health. One clinically important, but often overlooked, cardiovascular consequence is that diabetic and obese patients have increased requirements for surgical treatments. Following surgery they have longer hospital stays and poorer survival compared to non-diabetic and lean patients [1-3]. Importantly, patients with metabolic syndrome are subject to a higher incidence of perioperative haemodynamic complications, even for non-cardiac related surgeries, which most likely relates to changes in autonomic control of the cardiovascular system [2,4-6].

Long-term changes in metabolism, such as during the metabolic syndrome [7], are characterised by increased muscle sympathetic nerve activity $[8,9]$ and increases in plasma (nor)epinephrine levels [10], suggesting overall central sympathetic over-activation [7]. Consequently, several ex vivo studies demonstrated decreased $\beta$-AR expression in [11-14] and reduced $\beta$-AR responsiveness of [14-17] the heart in diabetes, with similar reports in obesity [18-20]. Less attention has focused on $\alpha$-ARs, with ex vivo studies or studies in anaesthetised rats variably reporting unchanged [16,21], impaired [22,23] or enhanced $[24,25] \alpha$-AR activity in the metabolic syndrome.

While the long-term metabolic stress of diabetes and obesity leads to haemodynamic dysregulation $[4,26]$, cardiovascular function is also acutely challenged in the perioperative setting $[4,27]$. Diabetes and obesity are both known to augment cardiovascular responses to anaesthetics $[16,28,29]$; and the well described cardioprotective effects of volatile anaesthetics are reduced under conditions of metabolic stress [30]. For instance, sevoflurane elicited greater impairments in myocardial blood flow in a pilot study of type 2 diabetic patients [31]. Isoflurane anaesthesia also impairs baroreflex responsiveness [32], and obesity is associated with impaired baroreflex sympatho-inhibition [33]; both effects which are thought to be mediated via augmentation of central nervous system pathways. Furthermore, Amour et al. [16] showed in isolated papillary muscles that type 1 diabetes attenuated the potentiation of $\alpha$ - and $\beta$-AR responses by halogenated anaesthetics, suggesting an interaction between anaesthetic and metabolic-mediated $\alpha$ - and $\beta$-AR dysfunction. However, this approach does not address the peripheral and neural effects present in vivo, nor examine changes in type 2 diabetes. Furthermore, the lack of in vivo data under conscious conditions, limits the interpretation of anaesthetic effects on $\alpha$ - and $\beta$-AR function.

Therefore, the present study aimed to assess how isoflurane anaesthesia affects the $\alpha$ - and $\beta$-AR-mediated haemodynamic responses in type 2 diabetes in vivo. To assess the direct effects of anaesthesia we measured haemodynamic responses in free-moving conscious and in isoflurane anaesthetised type 2 diabetic (Zucker Diabetic Fatty (ZDF)) rats following $\alpha$ - and $\beta$-AR stimulation. To this end, rats were implanted with a radio telemetric transmitter and a vascular access port to measure in vivo abdominal aortic blood pressure and inject intravenous drugs, respectively [34]. These measures were repeated in obese (Zucker) rats to determine whether the observed changes were a specific effect of type 2 diabetes, or a more general feature of metabolic syndrome.

\section{Materials and methods}

Animals

All procedures were approved by the University of Otago Animal Ethics Committee and were conducted in accordance with the New Zealand Animal Welfare Act (1999). Zucker Diabetic Fatty (ZDF) rats are derived from a selected subset of the Zucker strain, which spontaneously develop diabetes from 12 weeks of age due to impaired pancreatic beta-cell function [35]. Zucker Obese rats have a homozygous missense mutation in the leptin receptor gene ( $\mathrm{fa} / \mathrm{fa}$ ) leading to impaired satiety signalling and hyperphagia [36,37]. These strains are well-accepted models of type 2 diabetes mellitus and obesity, respectively, and were compared to their own lean littermates as in-strain controls.

Male rats $(N=39$; Charles River Laboratories, Wilmington, MA, USA) were housed at $20 \pm 1^{\circ} \mathrm{C}$ under a 12 hour light-dark cycle and provided with food and water ad libitum. All ZDF animals were maintained on Purina 5008 diet (LabDiet ${ }^{\circ}$, St Louis, MO, USA) as recommended by the supplier, while Zucker rats were fed chow (Rat and Mouse cubes; Specialty Feeds, WA, Australia). Animals were gentled daily for one week prior to surgery (Figure 1a). Plasma samples were collected via the tail vein following an 8-hour fast 4 days prior to surgery. Plasma glucose concentrations were determined using a glucometer (Roche, Basel, Switzerland) and insulin was measured by ELISA (Millipore, Billerica, MA, USA).

\section{Surgical procedures}

Dual implantation of a radio telemeter and vascular access port was performed on 16-week old animals under $2-2.5 \%$ isoflurane anaesthesia (Minrad Inc, Bethlehem, PA, USA) as previously described [34] with strict adherence to aseptic procedures. Analgesia (5 mg. $\mathrm{kg}^{-1}$ carprofen; Norbrook, Newry, Northern Ireland) and antibiotic (30 mg. $\mathrm{kg}^{-1}$ trimethoprim and sulphamethazine; Virbac, Carros, France) were administered subcutaneously.

Vascular Access Ports (VAP ${ }^{\mathrm{m}}$; ROP-3H, hydromer-coated polyurethane, 3Fr; Access Technologies, Skokie, IL, USA) were primed with heparin sodium (100 IU.mL ${ }^{-1}$; Hospira Australia, Mulgrave, Australia). The VAP reservoir was secured on the back of the animal between the scapulae, 


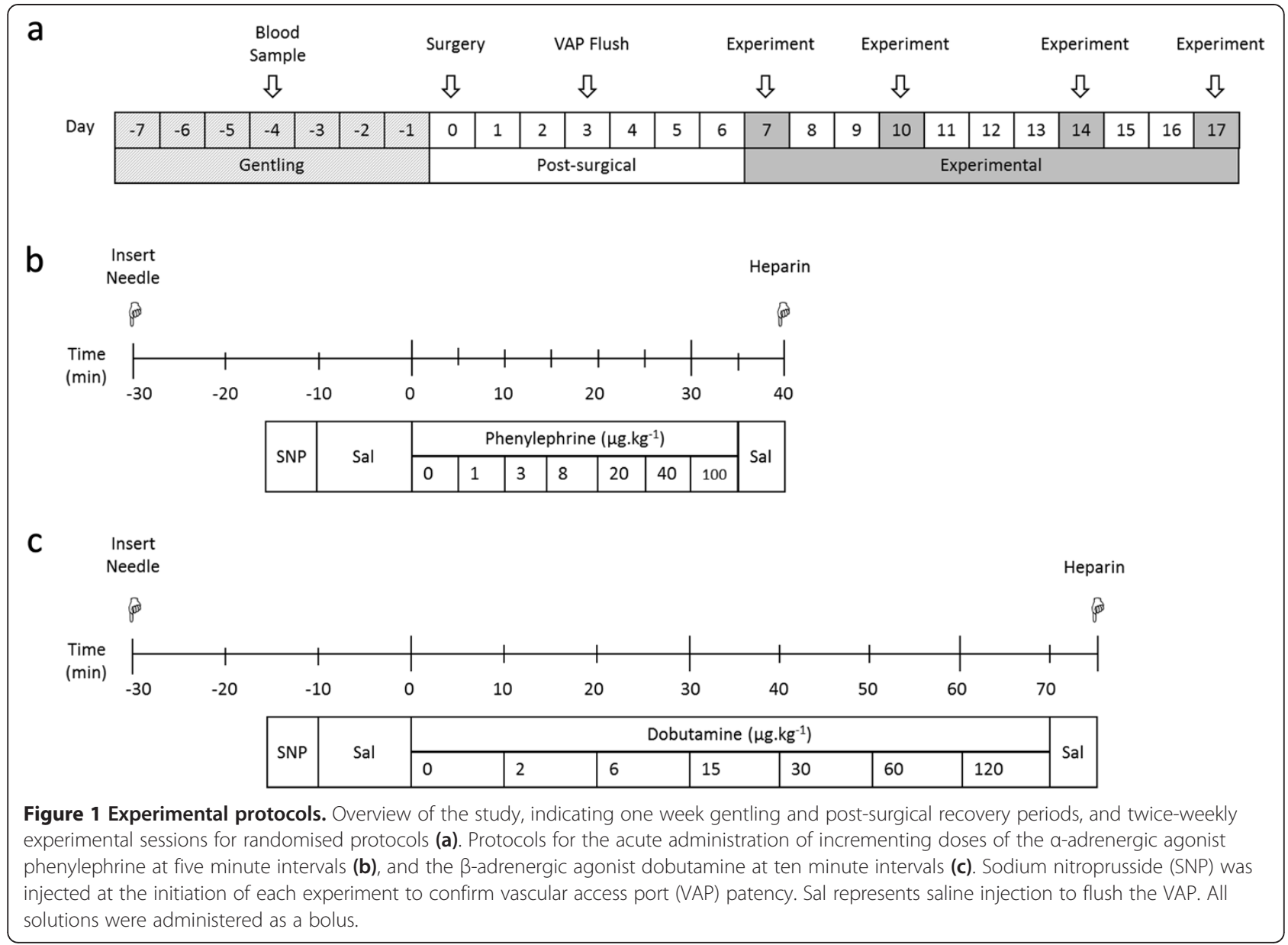

with the VAP cannula tunnelled subcutaneously to the femoral vein. A radio telemeter with pressure sensitive tip (TRM53P; Telemetry Research, Millar Instruments, Houston, TX, USA) was implanted into the abdominal aorta. Animals were allowed one-week post-surgical recovery before experimentation commenced (Figure 1a). The VAP was flushed with $0.4 \mathrm{~mL}$ heparin sodium $\left(100 \mathrm{IU} \cdot \mathrm{mL}^{-1}\right)$ at minimum twice-weekly to maintain patency.

\section{Experimental procedures}

Experiments were performed in random order twiceweekly to reduce stress to the animals, as well as ensuring complete drug clearance and avoiding potential desensitisation of adrenoceptors. This 3-4 day allowance between randomised experimental sessions, along with the 7 day post-surgical recovery period, also served to minimise potential effects of repeated exposure to volatile anaesthetics, generally described as lasting $24-72$ hours [38]. VAPs were accessed under strict aseptic conditions using a Huber point needle (PG24-625; Access Technologies, Skokie, IL, USA), following application of a short-acting local analgesic (5\% lignocaine/prilocaine; AstraZeneca, North Ryde, NSW, Australia).
Haemodynamic measures were equilibrated for $15 \mathrm{mi}-$ nutes following restraint and needle insertion. The nitric oxide donor sodium nitroprusside (SNP; $6.25 \mu \mathrm{g} . \mathrm{kg}^{-1}$ ) was administered at the beginning of each experimental session, as used previously to confirm VAP patency over the course of the study [34]. Isoflurane is a volatile anaesthetic commonly used in the clinical setting, due to its minimal haemodynamic effects and rapid recovery times. For measures under anaesthetised conditions, induction was undertaken at $5 \%$ isoflurane with maintenance at $2 \%$ isoflurane. Incrementing doses of the $\alpha$-adrenergic agonist phenylephrine (1-100 $\left.\mu \mathrm{g} . \mathrm{kg}^{-1}\right)$ and $\beta$-adrenergic agonist dobutamine (2-120 $\left.\mu \mathrm{g} \cdot \mathrm{kg}^{-1}\right)$ were administered at five or ten minute intervals, respectively (Figure $1 \mathrm{~b}$ and $\mathrm{c}$ ). Any access via the VAP was concluded by injection of $0.4 \mathrm{~mL}$ Heparin sodium (100 IU.mL ${ }^{-1}$ ) to prevent coagulation. All chemicals were from Sigma-Aldrich (St Louis, MO, USA) and diluted in saline $(0.9 \% \mathrm{NaCl}$; Baxter, Toongabbie, Australia) unless otherwise stated.

\section{Data and statistical analysis}

Blood pressure data was derived from the telemeter according to the manufacturer's instructions, and acquired 
using LabChart 7 software (ADInstruments, Dunedin, New Zealand). Heart rate (HR) and mean arterial pressure (MAP) were derived from blood pressure recordings using the LabChart ${ }^{\circ}$ blood pressure module, and averaged over every ten consecutive cycles. Basal haemodynamic data for an individual animal were averaged over up to four conscious replicates and up to two replicate anaesthetised measures. Haemodynamic responses were assessed as the calculated change between the peak response to and the baseline immediately preceding each individual bolus injection. Time course dynamics were assessed over 5 second averages. Statistical analysis was performed for baseline characteristics via t-test, or Mann-Whitney rank sums test where the assumptions were not met; or via two-way repeated measures ANOVA for all haemodynamic data. Differences between groups were identified using Student-Newman-Keuls post-hoc analysis (Sigmaplot ${ }^{\mathrm{tm}}$ 12.0, Systat Software Inc, Chicago, IL, USA) and significance assumed at the level of $p<0.05$. Data are expressed as mean \pm standard error of the mean (SE).

\section{Results}

Baseline characteristics and haemodynamics of type 2 diabetic rats

Type 2 diabetic rats exhibited body weights $25 \%$ higher than their non-diabetic littermates (Table 1). This was accompanied by significantly greater abdominal adiposity, as indicated by epididymal fat pad weight. Type 2 diabetic animals also exhibited both hyperglycaemia and hyperinsulinemia, characteristic of the condition.

Baseline haemodynamics were assessed under conscious resting conditions or following stabilisation of $2 \%$ isoflurane anaesthesia (Table 1). Type 2 diabetic animals were normotensive with a markedly reduced HR under conscious conditions; in agreement with multiple literature reports $[10,39]$. Isoflurane anaesthesia significantly reduced both HR and MAP in all animals, eliminating differences in HR.

\section{a-adrenergic sensitivity is increased in conscious and anaesthetised type 2 diabetic rats}

Administration of phenylephrine (PE), an $\alpha$-AR agonist, primarily elicited a rapid, transient increase in MAP in a dose-dependent manner (Figure 2). Conscious type 2 diabetic animals demonstrated a greater increase in MAP with the highest dose of phenylephrine (Figure 2a). It is unclear whether this represents maximal PE-mediated vasoconstriction, as the extreme bradycardia (Figure 2c) prevented testing of higher doses. However, higher doses of PE are unlikely to be used clinically, with a therapeutic dose range for PE of approximately $0.5-9 \mathrm{ug} \cdot \mathrm{kg}^{-1} \cdot \mathrm{min}^{-1}$ [40]. Under anaesthesia the maximal MAP response to $\alpha$-AR stimulation was not changed, however the increase in MAP at lower, therapeutic doses of PE was significantly reduced in both groups (Figure 2b). This isofluraneinduced decrease in pressure was less in the type 2 diabetic rats, accentuating the differential $\alpha$-AR sensitivity in diabetes in vivo.

Secondary to the changes in MAP, PE elicited a dosedependent reduction in HR (Figure $2 \mathrm{c}$ and $\mathrm{d}$ ). Conscious diabetic animals experienced a reduced bradycardic response to high-dose PE (Figure 2c). Given the greater maximum recorded peak MAP (Figure 2a), this indicates a limited baroreflex capacity in conscious type 2 diabetic rats (diabetic $-2.1 \pm 0.2$ bpm. $\mathrm{mmHg}^{-1}$ vs. non-diabetic $-3.0 \pm$

Table 1 Baseline characteristics and haemodynamics

\begin{tabular}{|c|c|c|c|c|}
\hline & Non-Diabetic & Diabetic & Lean & Obese \\
\hline Body weight (g) & $333 \pm 6$ & $417 \pm 14^{*}$ & $364 \pm 7$ & $584 \pm 16^{*}$ \\
\hline Epididymal fat weight (g) & $1.45 \pm 0.16$ & $6.38 \pm 0.67^{*}$ & $2.77 \pm 0.29$ & $17.57 \pm 1.04^{*}$ \\
\hline Epididymal fat/Tibia length $\left(\mathrm{g} . \mathrm{cm}^{-1}\right)$ & $0.40 \pm 0.06$ & $1.92 \pm 0.18^{*}$ & $0.65 \pm 0.07$ & $4.57 \pm 0.31^{*}$ \\
\hline Heart weight (g) & $1.49 \pm 0.06$ & $1.52 \pm 0.06$ & $1.37 \pm 0.06$ & $1.56 \pm 0.08$ \\
\hline Heart weight/Tibia length $\left(\mathrm{g} . \mathrm{cm}^{-1}\right)$ & $0.41 \pm 0.02$ & $0.44 \pm 0.02$ & $0.32 \pm 0.02$ & $0.40 \pm 0.02^{*}$ \\
\hline Fasting plasma glucose (mmol..-1 $\left.{ }^{-1}\right)$ & $6.4 \pm 0.4$ & $19.5 \pm 4.4^{*}$ & $6.6 \pm 0.3$ & $7.1 \pm 0.8$ \\
\hline Fasting plasma insulin (ng.mL ${ }^{-1}$ ) & $1.2 \pm 0.3$ & $8.0 \pm 2.2^{*}$ & $1.1 \pm 0.4$ & $12.8 \pm 3.2^{*}$ \\
\hline \multicolumn{5}{|l|}{ Mean arterial pressure $(\mathrm{mmHg})$} \\
\hline Conscious & $110.2 \pm 4.7$ & $114.4 \pm 3.5$ & $106.2 \pm 4.7$ & $125.9 \pm 5.5^{*}$ \\
\hline Anaesthetised & $87.5 \pm 4.4^{\dagger}$ & $90.8 \pm 7.6^{\dagger}$ & $86.1 \pm 5.8^{\dagger}$ & $111.2 \pm 5.0^{*}+$ \\
\hline \multicolumn{5}{|l|}{ Heart rate (bpm) } \\
\hline Conscious & $366 \pm 16$ & $317 \pm 11^{*}$ & $389 \pm 10$ & $391 \pm 10$ \\
\hline Anaesthetised & $314 \pm 10^{\dagger}$ & $292 \pm 4^{\dagger}$ & $365 \pm 7^{\dagger}$ & $365 \pm 6^{\dagger}$ \\
\hline
\end{tabular}

Baseline characteristics of 16 week old Zucker Diabetic Fatty (ZDF) and Zucker Obese rats and their lean littermates. *significantly different from control littermates, ${ }^{\dagger}$ significantly different anaesthetised vs. conscious, $n=6-9, p<0.05$, values are means $\pm \mathrm{SE}$. 
a

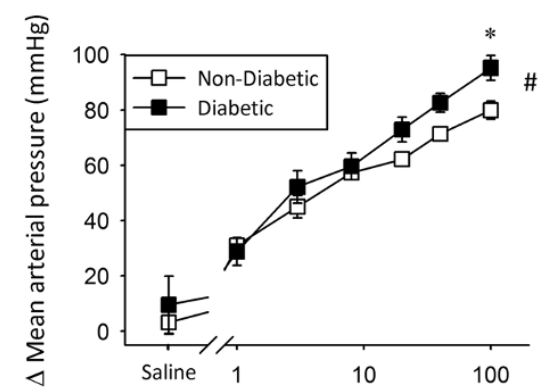

C

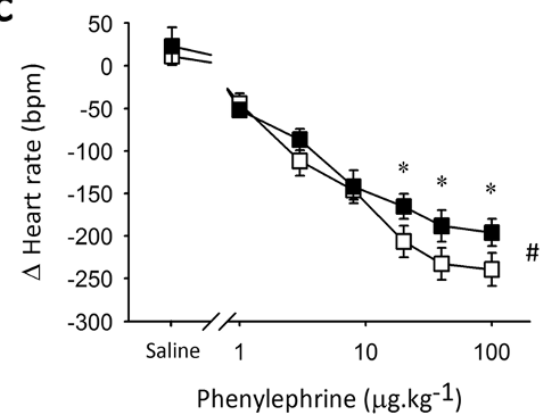

b

Anaesthetised

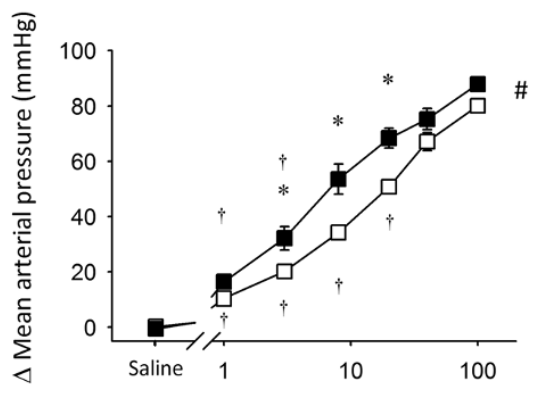

d

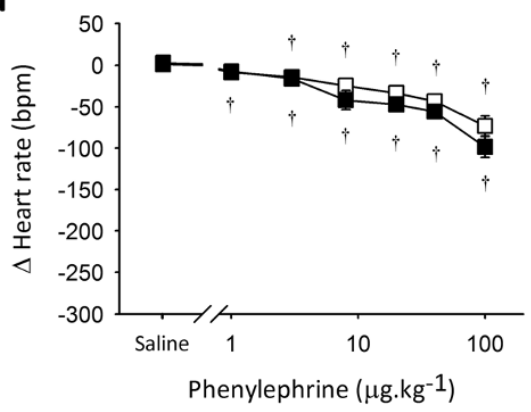

Figure 2 a-adrenoceptor agonist responses in Zucker Diabetic Fatty rats. Peak change in mean arterial pressure (top) and heart rate (bottom) in response to 1-100 $\mu \mathrm{g} \cdot \mathrm{kg}^{-1}$ phenylephrine under conscious conditions ( $\mathbf{a}$ and $\mathbf{c}$ ) and during isoflurane anaesthesia (b and d). * ${ }^{*}$ significantly different from non-diabetic littermate controls, ${ }^{\dagger}$ significantly different from conscious measure and \# significant overall group difference, $n=8, p<0.05$, values are means $\pm \mathrm{SE}$.

$0.3 \mathrm{bpm} . \mathrm{mmHg}^{-1}$ at $\left.100 \mu \mathrm{g} . \mathrm{kg}^{-1} ; p<0.05\right)$. Anaesthesia markedly reduced the baroreflex-mediated bradycardia in all animals, eliminating the between group differences.

\section{$\beta$-adrenergic sensitivity is reduced in conscious type 2 diabetic rats}

Administration of dobutamine, a non-specific $\beta$-AR agonist, primarily elicited a dose-dependent increase in HR in both non-diabetic and type 2 diabetic animals under all conditions (Figure 3). Conscious diabetic rats were less sensitive to dobutamine than their non-diabetic counterparts (Figure 3a), as evidenced by a significantly reduced response to the mid-dose of dobutamine $\left(15 \mu \mathrm{g} \cdot \mathrm{kg}^{-1}\right)$. This dose is within the therapeutic range of approximately 2-20 ug. $\mathrm{kg}^{-1} \cdot \mathrm{min}^{-1}$ [40], making the observed chronotropic difference particularly relevant for the clinical setting. In addition, similar percentage increases in heart rate have been described following injection of 3.2 and $12.2 \mu \mathrm{g} . \mathrm{kg}^{-1}$ dobutamine in healthy human volunteers [41]; indicating that effective doses are equivalent between the species. Isoflurane anaesthesia reduced the maximal $\beta$-ARmediated chronotropic response in non-diabetic animals (Figure 3b). Conversely, in type 2 diabetic animals anaesthesia increased $\beta$-AR sensitivity in the mid-range (Figure $3 \mathrm{~b}$ ) compared to the conscious condition, with no change at the maximal dose. Thus, isoflurane normalised $\beta$-AR responsiveness in type 2 diabetic rats $i n$ vivo.

Dobutamine administration also caused a transient decrease in MAP under all conditions, most likely attributable to vasodilation via stimulation of $\beta_{2}$-ARs in the vasculature (Figure 3c and d). No significant differences in $\beta$-AR-mediated vasodilation were observed between non-diabetic and type 2 diabetic animals.

\section{Baseline characteristics and haemodynamics of obese rats} Following the findings of altered adrenoceptor function and responses to anaesthesia in type 2 diabetic animals in vivo, we aimed to determine whether these disturbances were specifically attributable to hyperglycaemia or a general feature of obesity and the metabolic syndrome.

Zucker obese rats exhibited markedly higher body weights than their lean littermates, with an average $60 \%$ increase, accompanied by a large increase in epididymal fat pad weight (Table 1). Cardiac hypertrophy became evident in obese animals when heart weight was adjusted to tibia length as a proxy for body size, despite no significant differences in tibia length (data not shown). Metabolic assessment showed hyperinsulinemia with normal glucose levels in obese animals, indicating insulin resistance. 


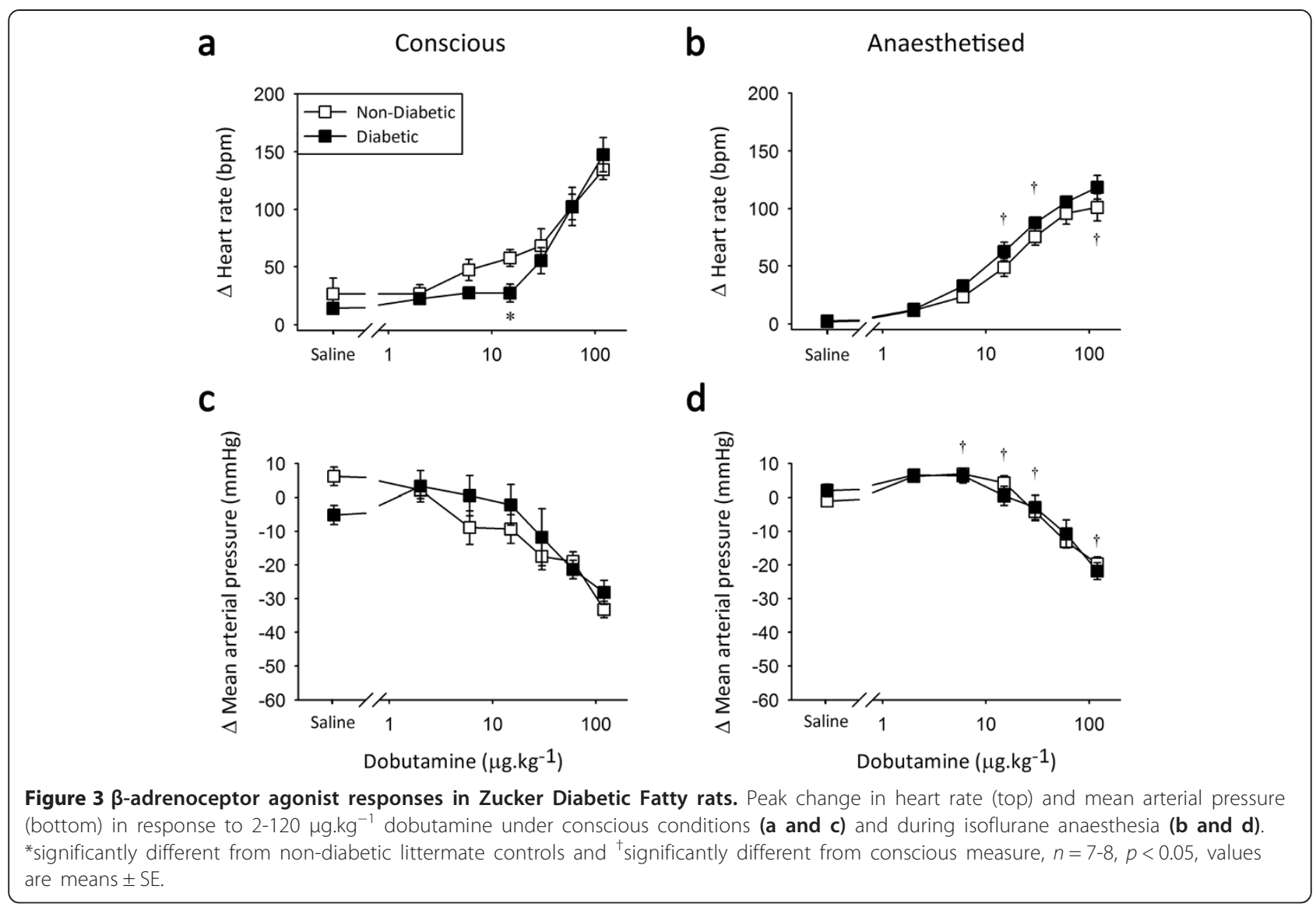

Similar to previous reports $[18,42]$, obese animals displayed significantly increased MAP under both conscious and anaesthetised conditions (Table 1).

\section{a-adrenergic sensitivity is increased in conscious and anaesthetised obese rats}

Conscious obese rats showed a larger increase in MAP with $\alpha$-AR stimulation than their lean littermates (Figure 4a), suggesting increased $\alpha$-AR sensitivity in obesity in vivo. Isoflurane anaesthesia reduced the MAP response to low doses of PE in lean, but not obese, animals (Figure 4b), exacerbating the differential $\alpha$-AR-mediated vasoconstriction.

Under conscious conditions, obese rats exhibited increased baroreflex-mediated bradycardia in response to $8 \mu \mathrm{g} . \mathrm{kg}^{-1}$ PE (Figure 4c). However, with a greater corresponding increase in MAP (Figure 4a), this represents an unchanged baroreflex sensitivity (lean $-2.3 \pm 0.3$ vs. obese $-2.5 \pm 0.2$ bpm. $\mathrm{mmHg}^{-1} ; \mathrm{NS}$ ). Conscious obese rats also showed a trend toward reduced maximal bradycardia (Figure 4c; $p=0.052$ ), similar to that seen in type 2 diabetic animals. Baroreflex-mediated bradycardia was generally reduced during anaesthesia (Figure $4 \mathrm{~d}$ ), as seen in the ZDF rats, removing potential obesity-derived differences.

\section{$\beta$-adrenergic sensitivity is reduced in conscious obese rats}

Conscious obese rats displayed a reduced $\beta$-AR response following dobutamine administration compared to their lean counterparts (Figure 5a), an effect most pronounced at the mid-dose $\left(15 \mu \mathrm{g} . \mathrm{kg}^{-1}\right)$ similar to type 2 diabetic rats. Isoflurane anaesthesia significantly reduced the maximal $\beta$-AR-mediated chronotropic response in both groups (Figure $5 \mathrm{~b}$ ), being particularly effective in lean animals where the response was reduced across the entire dose curve. The general reduction in $\beta$-AR response during anaesthesia eliminated sensitivity differences between the obese animals and their controls.

Dobutamine-mediated vasodilation was slightly greater in obese than lean rats, with variable significance across the dose-response curve (Figure 5c). Under anaesthesia the differences between lean and obese animals were absent (Figure 5d).

\section{a-adrenergic responses are prolonged by anaesthesia and} type 2 diabetes or obesity

The interesting observation that the differential $\alpha$-AR responsiveness in type 2 diabetes and obesity in vivo was exacerbated by anaesthesia was further considered with 


\section{a}

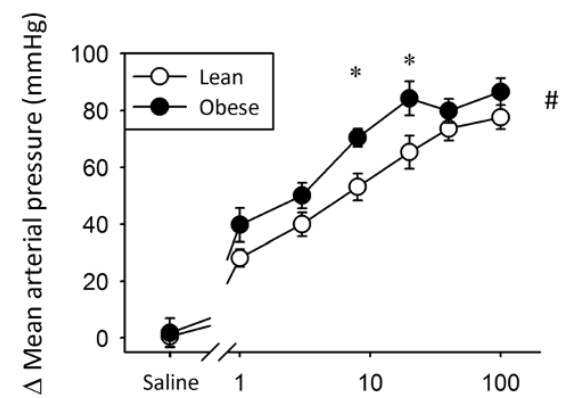

C

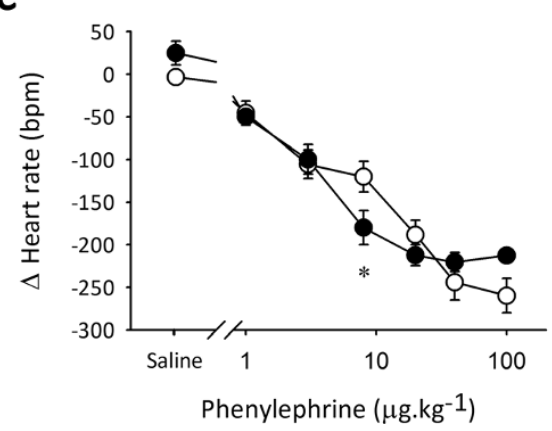

b

Anaesthetised

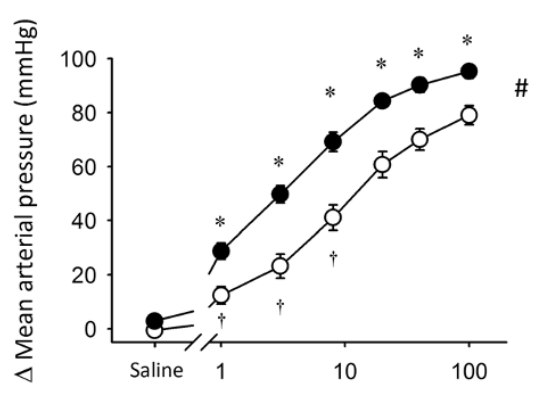

d

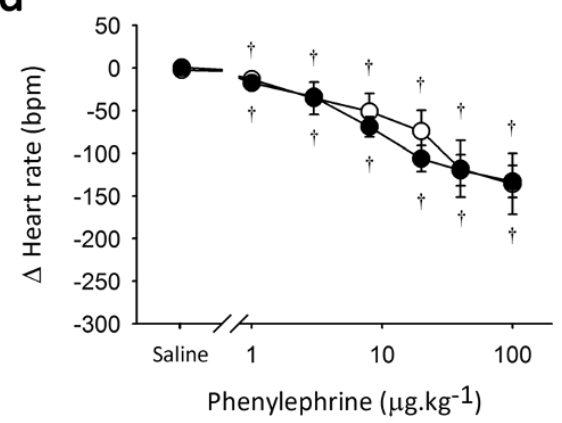

Figure 4 a-adrenoceptor agonist responses in Zucker Obese rats. Peak change in mean arterial pressure (top) and heart rate (bottom) in response to $1-100 \mu \mathrm{g} \cdot \mathrm{kg}^{-1}$ phenylephrine under conscious conditions (a and $\mathbf{c}$ ) and during isoflurane anaesthesia (b and d). ${ }^{*}$ significantly different from lean littermate controls, ${ }^{\dagger}$ significantly different from conscious measure and \# significant overall group difference, $n=8, p<0.05$, values are means $\pm \mathrm{SE}$.

respect to the temporal dynamics of the vasoconstriction. With the rapid effects of PE, no change in time to peak response or time to return to plateau of note was apparent between any groups or conditions. However, observation of the full response time courses indicated significant effects of both anaesthesia and diabetes to prolong the elevated MAP following $\alpha$-AR stimulation (Figure 6a-c). Similar, and more pronounced, prolongation of the $\alpha$-AR effects was observed in obese animals (Figure 6d-f). A significant interaction between anaesthesia and obesity was particularly apparent following administration of $20 \mu \mathrm{g} . \mathrm{kg}^{-1}$ PE (Figure 6d). Isoflurane anaesthesia did not prolong the MAP response to equivalent $\alpha$-AR stimulation in lean animals. Increasing the $\alpha$-AR agonist concentration uncovered independent, but additive, effects of obesity and anaesthesia to exacerbate $\alpha$-ARmediated vasoconstriction (Figure 6e and f). Notably, anaesthesia appeared to primarily exacerbate the MAP response at the early to mid-time points, while obesity prolonged MAP elevation in the later stages of the response.

The time taken to reach peak $\beta$-AR HR response was similar in all conscious animals (non-diabetic $31 \pm 8$ vs. diabetic $48 \pm 9 \mathrm{~s}$, lean $34 \pm 4$ vs. obese $38 \pm 5 \mathrm{~s}$ at $120 \mu \mathrm{g}$. $\mathrm{kg}^{-1}$; NS). However, during anaesthesia the time to peak response was significantly prolonged in control animals compared to their diseased littermates (non-diabetic $68 \pm$ 6 vs. diabetic $47 \pm 3$ s, lean $66 \pm 5$ vs. obese $39 \pm 4$ s at $\left.120 \mu \mathrm{g} . \mathrm{kg}^{-1} ; p<0.05\right)$, despite similar peak values (Figures $3 \mathrm{~b}$ and $5 \mathrm{~b}$ ). Moreover, the time required for HR to return to plateau from peak dobutamine response was slightly faster in conscious type 2 diabetic animals at the maximal dose (non-diabetic $177 \pm 41$ vs. diabetic $94 \pm$ $19 \mathrm{~s} ; p<0.05)$. Isoflurane non-selectively slowed this HR recovery time to plateau. Therefore, alterations in the dynamics of $\beta$-AR function in type 2 diabetes and obesity, particularly during anaesthesia, may be reflected more by a briefer, rather than smaller, response.

\section{Anaesthesia differentially affects adrenergic responses in non-diabetic and type 2 diabetic rats}

The broad findings of this study can be summarised in the peak responses to mid-doses of PE $\left(20 \mu \mathrm{g} \cdot \mathrm{kg}^{-1}\right)$ and dobutamine $\left(15 \mu \mathrm{g} \cdot \mathrm{kg}^{-1}\right)$. Conscious type 2 diabetic and obese rats exhibited significantly increased $\alpha$-adrenergic and reduced $\beta$-adrenergic sensitivity. Isoflurane anaesthesia decreased $\alpha$-adrenergic responsiveness in non-diabetic but not in type 2 diabetic animals, while it increased $\beta$-adrenergic responses in type 2 diabetic rats with no effect on control responses (Figure 7). Anaesthetised obese rats similarly exhibited maintenance of the increased $\alpha$-AR sensitivity, and normalisation of the $\beta$-adrenergic 
a

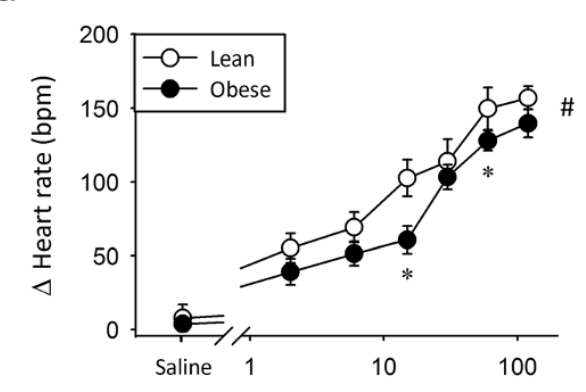

C

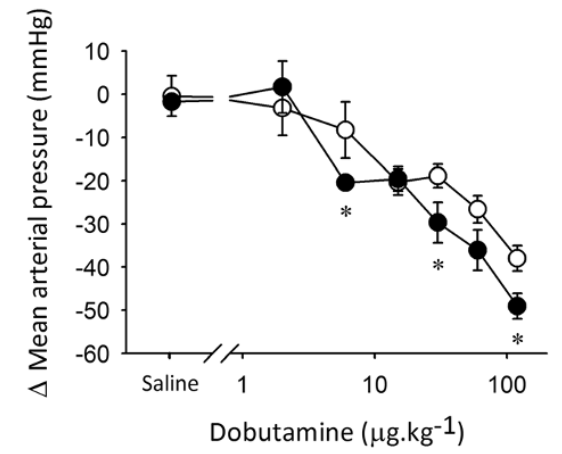

b

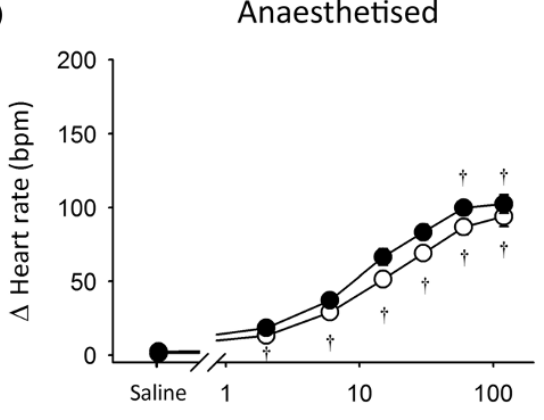

d

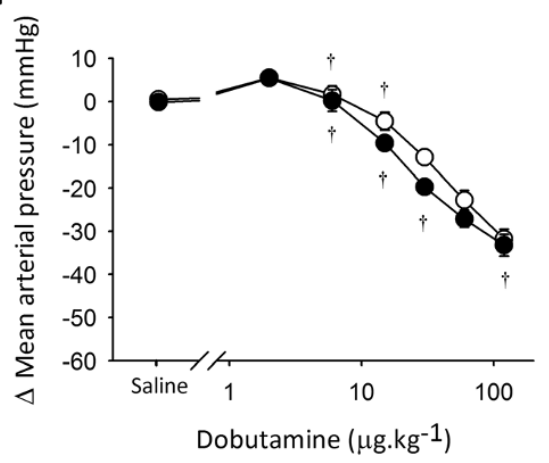

Figure 5 -adrenoceptor agonist responses in Zucker Obese rats. Peak change in heart rate (top) and mean arterial pressure (bottom) in response to 2-120 $\mu \mathrm{g} \cdot \mathrm{kg}^{-1}$ dobutamine under conscious conditions (a and $\mathbf{c}$ ) and during isoflurane anaesthesia (b and d). ${ }^{*}$ significantly different from lean littermate controls, ${ }^{\dagger}$ significantly different from conscious measure and \# significant overall group difference, $n=7-9, p<0.05$, values are means $\pm \mathrm{SE}$.

responses due to a reduction in the control animals only (data not shown). Thus, anaesthetised type 2 diabetic and obese animals experience a significantly accentuated adrenergic load.

\section{Discussion}

This is the first study to determine the interaction between $\alpha$ - and $\beta$-adrenergic function and isoflurane anaesthesia in vivo under physiological conscious and anaesthetised conditions. This conscious-anaesthesia approach reveals augmented vascular $\alpha$-AR sensitivity and reduced cardiac chronotropic $\beta$-AR sensitivity in conscious free-moving type 2 diabetic and obese animals. Moreover, isoflurane anaesthesia exacerbated the increased vascular $\alpha$-AR sensitivity in both disease models, while normalising the chronotropic $\beta$-AR responses in obese rats and surprisingly increasing the chronotropic $\beta$-AR sensitivity in type 2 diabetic rats. These results show that chronic metabolic stress, such as during type 2 diabetes and obesity, alters $\alpha$ - and $\beta$-adrenoceptor function in vivo, its dynamics and the interaction with anaesthesia; reducing the haemodynamic capacity of the cardiovascular system to compensate during times of acute stress. Furthermore, the differential $\alpha$ - and $\beta$-adrenergic responses described in type 2 diabetes and obesity during isoflurane anaesthesia emphasise the importance of examining pharmacological effects under physiological conditions.

Several studies have found increased $\alpha$-AR vascular reactivity in isolated and anaesthetised preparations from both type 1 and type 2 diabetic $(20,30,38)$ and obese models $(28,29,37)$. Alternatively, some studies reported unchanged $[18,21]$ or reduced $[43,44]$ vascular $\alpha-A R$ responses. However use of low phenylephrine doses that also failed to discern a difference in our study [18] or nonspecific $\alpha$-AR stimulation with noradrenaline [43,44], may explain these differences. The present study shows augmented vascular $\alpha$-AR responsiveness, in magnitude and in duration, in conscious type 2 diabetic and obese animals, at clinical doses of phenylephrine (32).

The reduced cardiac $\beta$-AR sensitivity observed aligns with and extends literature reports. During the metabolically compromised state of diabetes, it is suggested that the sympathetic drive to the heart is increased [4,7], eventually desensitising the adrenergic control of the heart and reducing its function [45]. Reduced $\beta$-AR activity has been described in both isolated heart [14-16,46] and in anaesthetised in vivo preparations [12] of streptozotocininduced type 1 diabetes. Furthermore, we have recently described the loss of $\beta$-AR responsiveness with type 2 diabetes in human right atrial cardiac muscles [17]. 

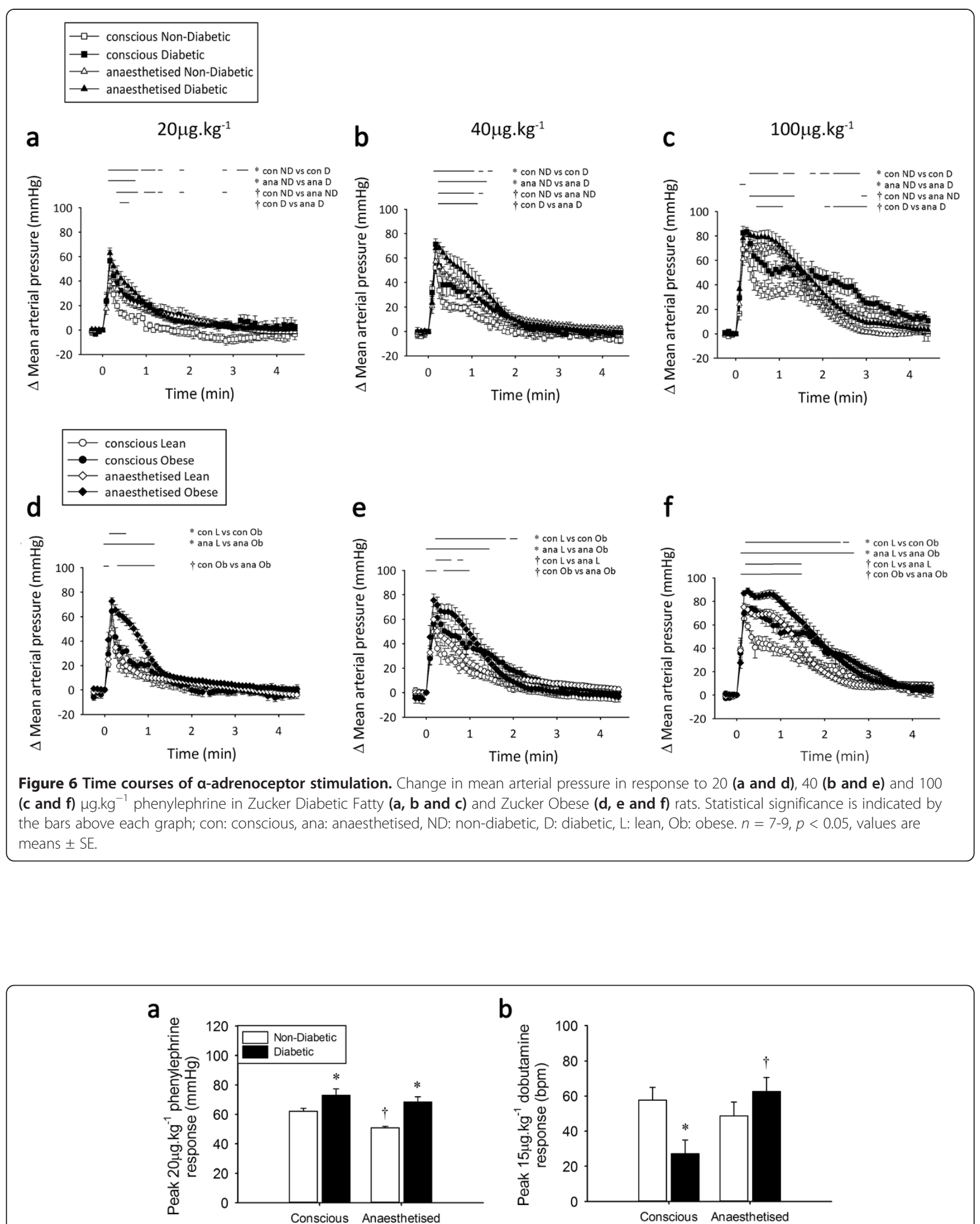

Figure 7 Summary of $\boldsymbol{\alpha}$ - and $\boldsymbol{\beta}$-adrenoceptor function in conscious and anaesthetised Zucker Diabetic Fatty rats. Peak responses to mid-dose phenylephrine (a) or dobutamine (b). * significantly different from lean littermate controls, ${ }^{\dagger}$ significantly different from conscious measure, $n=7-9, p<0.05$, values are means $\pm \mathrm{SE}$. 
Similar findings of reduced $\beta$-AR function have been derived from heart tissue from $[19,20]$ and a single report in conscious [18] obese rodents. However, the present study provides the first evidence of increased and prolonged vascular $\alpha$-AR sensitivity and reduced chronotropic $\beta$-AR sensitivity in well-developed models of both type 2 diabetes and obesity in vivo under conscious conditions.

While the mechanisms underlying the altered AR function are poorly understood, and determination was not the aim of this study, changes in AR expression have been implicated. Elevated cardiovascular $\alpha_{1}$-AR expression has been described in various models of the metabolic syndrome [46-48], although decreased $\alpha$-AR density has also been reported $[48,49]$. This $\alpha_{1}$-AR variability is proposed to be attributable to disease duration $[24,49]$, with a biphasic expression pattern providing a compensatory response to the progressive $\alpha$-AR sensitisation $[48,49]$. However, during ganglionic blockade $\alpha$-AR responsiveness was found to be unchanged, indicating that the effect may originate downstream [21]. Decreased expression of $\beta_{1}$-ARs was shown in myocardium of type 1 diabetic rodent models $[11,13,50]$. However, we found unchanged $\beta_{1}$-AR expression in right atrial tissue from type 2 diabetic patients [17]. Similarly, Carroll et al. [42] found unchanged overall $\beta$-AR density in obese rabbit ventricles, and similar to $\alpha$-ARs, suggested that defective $\beta$-AR function in obesity may originate downstream of the receptors themselves. Moreover, we have recently shown that the haemodynamic effects observed using our technique are not due to the potential confounders of volume or injection stress in conscious animals [34]. Thus, further research, particularly into expression and function of $\alpha-A R$ in the vasculature and $\beta$-AR in the sinoatrial node, is warranted to explain these haemodynamic and chronotropic differences.

Much of the previous experimental evidence for $\alpha$ - and $\beta$-AR-dysfunction has been derived from models of type 1 diabetes, and conducted in anaesthetised or isolated heart or vessel preparations. Therefore, this study, using improved conscious in vivo techniques, confirms the relevance of these $\alpha$ - and $\beta$-AR-dysfunctions in type 2 diabetes and obesity under physiological conditions and provides valuable new insights. Additionally, the paucity of suitable data in conscious animals has made it difficult to elucidate the effects of anaesthetics per se, and few investigations have addressed this issue. Amour et al. [16] showed in an interesting study that halogenated anaesthetics, including isoflurane, increased both $\alpha$-AR and $\beta$-AR inotropic responses in isolated hearts. This is supported by our observation of enhanced $\beta$-AR-generated HR responses in type 2 diabetic animals, but not by the absence of isoflurane-potentiated $\beta$-AR chronotropic responses in non-diabetic rats or the reduced $\alpha$-AR sensitivity. This indicates the importance of in vivo investigations, including neural, hormonal and vascular feedbacks, which are most likely geared to compensate for excessive fluctuations in the cardiovascular system.

It is unclear how defects exclusively at the $\alpha$ - and $\beta$ ARs themselves would directly interact with anaesthesia. Likewise, simple interruption of central autonomic signalling by anaesthetics would be unlikely to selectively interact with $\alpha$-AR function. The phenylephrinegenerated baroreflex-induced changes in HR were overall markedly depressed under isoflurane. Thus, it could be speculated that isoflurane prevents appropriate central control of sympathetic withdrawal during MAP elevation in the vasculature causing an anaesthetic-mediated exacerbation of $\alpha$-AR sensitisation in type 2 diabetic and obese rats.

By utilising models of type 2 diabetes and obesity with a common underlying defect in leptin signalling, we were able to directly address the influence of hyperglycaemia. The observed alterations in $\alpha$ - and $\beta$-AR function were broadly similar between type 2 diabetic and obese rats. Thus, these impairments are likely to be a function of the general metabolic syndrome components of overweight and insulin resistance, rather than the hyperglycaemic phenotype of diabetes; in agreement with previous findings that $\alpha$ - and $\beta$-AR dysfunction is not tied to the development of type 2 diabetes [51]. Furthermore, as the effects were more severe in morbidly obese rats, and less pronounced in the overweight type 2 diabetic animals, it appears that obesity may be the primary causal defect.

Regardless of the cause of exacerbated metabolic $\alpha$ and $\beta$-AR dysfunction, differences in $\alpha$ - and $\beta$-AR responsiveness (in magnitude and duration) remain an important consideration in this large patient group. During chronic metabolic stress, such as obesity and type 2 diabetes, sympathetic drive to the heart is suggested to be increased [4,7]; which may be partially offset by the observed reduction in $\beta$-AR sensitivity. Enhanced and prolonged $\alpha$-AR responsiveness and the resultant chronic excess cardiovascular pressure could lead to cardiac complications, including increased afterload, cardiac remodelling and hypertrophy [52]. During anaesthesia, the dual effects of exacerbating differences in $\alpha$-AR response and normalising $\beta$-AR function will likely act in concert in type 2 diabetes and obesity to further increase cardiovascular stress. This indicates that chronic metabolic stress limits the capacity of the cardiovascular system to respond when challenged by acute stressors such as anaesthesia. In particular, the interaction between metabolic syndrome and anaesthesia to exaggerate phenylephrine-mediated elevations in MAP suggests that type 2 diabetic and obese patients may be exposed to increased pharmacological stress during surgery. 


\section{Conclusion}

In summary, this study is the first to determine the haemodynamic consequences of altered $\alpha$ - and $\beta$-AR function in conscious type 2 diabetic and obese animals, and the interaction between adrenergic dysfunction and isoflurane anaesthesia in vivo. Under conscious physiological conditions, type 2 diabetic and obese rats exhibited increased $\alpha-A R$ and decreased $\beta$-AR responses. Meanwhile, during anaesthesia, enhanced $\alpha$-AR sensitivity and normalised $\beta$-AR function may further impair cardiovascular function in type 2 diabetes and obesity.

\section{Competing interests}

The authors declare that they have no competing interests.

\section{Authors' contributions}

All authors contributed to research design and interpretation of data. $\mathrm{RL}$ conceived of the study, with experiments and analysis performed by $C B$ and $A d L$. $C B$ drafted the manuscript and revised it with input from all authors. All authors approved the final version of the manuscript.

\section{Acknowledgements}

This work was funded by the New Zealand Lottery Grants Board, Department of Internal Affairs, Wellington, New Zealand; Department of Physiology, University of Otago, Dunedin, New Zealand; Otago School of Medical Sciences, University of Otago, Dunedin, New Zealand.

\section{Received: 13 August 2014 Accepted: 1 December 2014}

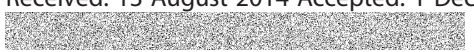

\section{References}

1. Alserius T, Hammar N, Nordqvist T, Ivert T: Improved survival after coronary artery bypass grafting has not influenced the mortality disadvantage in patients with diabetes mellitus. J Thorac Cardiovasc Surg 2009, 138(5):1115-1122.

2. Tolpin DA, Collard CD, Lee V-V, Elayda MA, Pan W: Obesity is associated with increased morbidity after coronary artery bypass graft surgery in patients with renal insufficiency. J Thorac Cardiovasc Surg 2009, 138(4):873-879.

3. Tung $\mathrm{A}$ : Anaesthetic considerations with the metabolic syndrome. $\mathrm{Br} \mathrm{J}$ Anaesth 2010, 105(suppl 1):i24-i33.

4. Vinik Al, Ziegler D: Diabetic Cardiovascular Autonomic Neuropathy. Circulation 2007, 115(3):387-397.

5. Vohra A, Kumar S, Charlton AJ, Olukoga AO, Boulton AJM, McLeod D: Effect of Diabetes Mellitus on the cardiovascular responses to induction of anaesthesia and tracheal intubation. Br J Anaesth 1993, 71(2):258-261.

6. Knüttgen D, Weidemann $D$, Doehn M: Diabetic autonomic neuropathy: abnormal cardiovascular reactions under general anesthesia. Klin Wochenschr 1990, 68(23):1168-1172.

7. Lambert GW, Straznicky NE, Lambert EA, Dixon JB, Schlaich MP: Sympathetic nervous activation in obesity and the metabolic syndrome-Causes, consequences and therapeutic implications. Pharmacol Ther 2010, 126(2):159-172.

8. Agapitov AV, Correia MLG, Sinkey CA, Haynes WG: Dissociation Between Sympathetic Nerve Traffic and Sympathetically Mediated Vascular Tone in Normotensive Human Obesity. Hypertension 2008, 52(4):687-695.

9. Huggett RJ, Scott EM, Gilbey SG, Stoker JB, Mackintosh AF, Mary DASG Impact of Type 2 Diabetes Mellitus on Sympathetic Neural Mechanisms in Hypertension. Circulation 2003, 108(25):3097-3101.

10. Marsh SA, Powell PC, Agarwal A, Dell'Italia LJ, Chatham JC: Cardiovascular dysfunction in Zucker obese and Zucker diabetic fatty rats: role of hydronephrosis. Am J Physiol Heart Circ Physiol 2007, 293(1):H292-H298.

11. Matsuda N, Hattori Y, Gando S, Akaishi Y, Kemmotsu O, Kanno M: Diabetes-induced down-regulation of $\beta 1$-adrenoceptor mRNA expression in rat heart. Biochem Pharmacol 1999, 58(5):881-885.

12. Bidasee KR, Zheng H, Shao C-H, Parbhu SK, Rozanski GJ, Patel KP: Exercise training initiated after the onset of diabetes preserves myocardial function: effects on expression of $\beta$-adrenoceptors. J Appl Physiol 2008, 105(3):907-914.

13. Dinçer ÜD, Bidasee KR, Güner ફ̧, Tay A, Özçelikay AT, Altan VM: The Effect of Diabetes on Expression of $\beta 1-, \beta 2-$, and $\beta 3$-Adrenoreceptors in Rat Hearts. Diabetes 2001, 50(2):455-461.

14. Lahaye SLD, Gratas-Delamarche A, Malardé L, Vincent S, Zguira MS, Morel SL, Delamarche P, Zouhal H, Carré F, Bekono FR: Intense exercise training induces adaptation in expression and responsiveness of cardiac $\beta$-adrenoceptors in diabetic rats. Cardiovasc Diabetol 2010, 9:72.

15. Dinçer ÜD, Onay A, Arı N, Özçelikay AT, Altan VM: The effects of diabetes on $\beta$-adrenoceptor mediated responsiveness of human and rat atria. Diabetes Res Clin Pract 1998, 40(2):113-122.

16. Amour J, David J-S, Vivien B, Coriat P, Riou B: Interaction of Halogenated Anesthetics with $\alpha$ - and $\beta$-Adrenoceptor Stimulations in Diabetic Rat Myocardium. Anesthesiology 2004, 101(5):1145-1152.

17. Lamberts RR, Lingam SJ, Wang H-Y, Bollen IA, Hughes G, Galvin IF, Bunton RW, Bahn A, Katare R, Baldi JC, Williams MJ, Saxena P, Coffey S, Jones PP: Impaired relaxation despite upregulated calcium-handling protein atrial myocardium from type 2 diabetic patients with preserved ejection fraction. Cardiovasc Diabetol 2014, 13:72.

18. Buñag RD, Tomita T, Krizsan D: Renovascular beta adrenergic hypersensitivity and hyperinsulinemia in rats with dietary-induced obesity. J Pharmacol Exp Ther 1990, 255(1):325-332.

19. Strassheim D, Houslay MD, Milligan G: Regulation of cardiac adenylate cyclase activity in rodent models of obesity. Biochem J 1992, 283(1):203-208.

20. Chatelain P, Robberecht P, Neef P, Camus J-C, Poloczek P, Christophe J: Impairment of Hormone-Stimulated cardiac adenylate cyclase activity in the genetically obese (fa/fa) Zucker rat. Pflügers Archives 1981, 390(1):10-16.

21. Ruggeri P, Brunori A, Cogo CE, Storace D, Di Nardo F, Burattini R: Enhanced sympathetic reactivity associates with insulin resistance in the young Zucker rat. Am J Physiol Regul Integr Comp Physiol 2006, 291(2):R376-R382.

22. Mita M, Kuramoto T, Ito K, Toguchi-Senrui N, Hishinuma S, Walsh MP, Shoji M: Impairment of a1-adrenoceptor-mediated contractile activity in caudal arterial smooth muscle from Type 2 diabetic Goto-Kakizaki rats. Clin Exp Pharmacol Physiol 2010, 37(3):350-357.

23. Schreihofer AM, Hair CD, Stepp DW: Reduced plasma volume and mesenteric vascular reactivity in obese Zucker rats. Am J Physiol Regul Integr Comp Physiol 2004, 288(1):R253-R261.

24. Naik J, Xiang L, Hester R: Enhanced role for RhoA-associated kinase in adrenergic-mediated vasoconstriction in gracilis arteries from obese Zucker rats. Am J Physiol Regul Integr Comp Physiol 2006, 290(1):R154-R161.

25. Naik J, Xiang L, Hodnett B, Hester R: Alpha-adrenoceptor-mediated vasoconstriction is not involved in impaired functional vasodilation in the obese Zucker rat. Clin Exp Pharmacol Physiol 2008, 35(5-6):611-616.

26. Després J-P: Targeting abdominal obesity and the metabolic syndrome to manage cardiovascular disease risk. Heart 2009, 95(13):1118-1124.

27. Oakley I, Emond L: Diabetic cardiac autonomic neuropathy and anesthetic management: review of the literature. AANA J 2011, 79(6):473-479.

28. Kasai T, Hirose M, Matsukawa T, Takamata A, Tanaka Y: The vasoconstriction threshold is increased in obese patients during general anaesthesia. Acta Anaesthesiol Scand 2003, 47(5):588-592.

29. Crespo MJ, Marrero M, Cruz N, Quidgley J, Creagh O, Torres H, Rivera K: Diabetes alters cardiovascular responses to anaesthetic induction agents in STZ-diabetic rats. Diab Vasc Dis Res 2011, 8(4):299-302.

30. van den Brom CE, Bulte CS, Loer SA, Bouwman RA, Boer C: Diabetes, perioperative ischaemia and volatile anaesthetics: consequences of derangements in myocardial substrate metabolism. Cardiovasc Diabetol 2013, 12:42.

31. Bulte C, van den Brom C, Loer S, Boer C, Bouwman R: Myocardial blood flow under general anaesthesia with sevoflurane in type 2 diabetic patients: a pilot study. Cardiovasc Diabetol 2014, 13:62.

32. Yoshimoto T, Eguchi K, Sakurai H, Ohmichi Y, Hashimoto T, Ohmichi M Morimoto A, Yamaguchi Y, Ushida T, Iwase S, Sugenoya J, Kumazawa T: Frequency components of systolic blood pressure variability reflect vasomotor and cardiac sympathetic functions in conscious rats. J Physiol Sci 2011, 61(5):373-383.

33. Huber DA, Schreihofer AM: Attenuated baroreflex control of sympathetic nerve activity in obese Zucker rats by central mechanisms. J Physiol 2010, 588(9):1515-1525. 
34. Bussey CT, de Leeuw AE, Cook RF, Ashley Z, Schofield J, Lamberts RR: Dual implantation of a radio-telemeter and vascular access port allows repeated hemodynamic and pharmacological measures in conscious lean and obese rats. Lab Anim 2014, 48(3):250-260.

35. Paulsen SJ, Vrang N, Larsen LK, Larsen PJ, Jelsing J: Stereological assessment of pancreatic beta-cell mass development in male Zucker Diabetic Fatty (ZDF) rats: correlation with pancreatic beta-cell function. J Anat 2010, 217(5):624-630.

36. Phillips MS, Liu Q, Hammond HA, Dugan V, Hey PJ, Caskey CT, Hess JF: Leptin receptor missense mutation in the fatty Zucker rat. Nat Genet 1996, 13:18-19.

37. Chua SC, White DW, Wu-Peng XS, Liu S-M, Okada N, Kershaw EE, Chung WK Power-Kehoe L, Chua M, Tartaglia LA, Leibel RL: Phenotype of fatty due to Gln269Pro mutation in the leptin receptor (Lepr). Diabetes 1996, 45(8):1141-1143.

38. Lucchinetti E, Aguirre J, Feng J, Zhu M, Suter M, Spahn DR, Härter L, Zaugg M: Molecular Evidence of Late Preconditioning After Sevoflurane Inhalation in Healthy Volunteers. Anesth Analg 2007, 105(3):629-640.

39. Radovits T, Korkmaz S, Loganathan S, Barnucz E, Bömicke T, Arif R, Karck M, Szabó G: Comparative investigation of the left ventricular pressure-volume relationship in rat models of type 1 and type 2 diabetes mellitus. Am J Physiol Heart Circ Physiol 2009, 297(1):H125-H133.

40. Overgaard CB, Džavík V: Inotropes and Vasopressors: Review of Physiology and Clinical Use in Cardiovascular Disease. Circulation 2008, 118(10):1047-1056.

41. Pousset $F$, Chalon S, Thomaré $P$, Diquet B, Lechat $P$ : Evaluation of cardiac beta 1-adrenergic sensitivity with dobutamine in healthy volunteers. $\mathrm{Br} \mathrm{J}$ Clin Pharmacol 1995, 39(6):633-639.

42. Carroll J, Kyser C, Martin M: beta-Adrenoceptor density and adenylyl cyclase activity in obese rabbit hearts. Int J Obes Relat Metab Disord 2002, 26(5):627-632

43. Leung JYT, Kwok EWY, Liu GY, Pang CCY: Attenuated a-adrenoceptor-mediated arterial and venous constrictions in rat models of diabetes. Eur J Pharmacol 2010, 642(1-3):128-133.

44. Song D, Hutchings SR, Pang CCY: Impaired in vivo venous constriction in conscious obese Zucker rats with metabolic syndrome. Naunyn-Schmied Arch Pharmacol 2006, 373(6):451-456.

45. Falcão-Pires I, Fontes-Sousa A, Lopes-Conceiçao L, Brás-Silva C, Leite-Moreira A: Modulation of myocardial stiffness by $\beta$-adrenergic stimulation-its role in normal and failing heart. Physiol Res 2011, 60(4):599-609.

46. Kamata K, Satoh T, Matsumoto T, Noguchi E, Taguchi K, Kobayashi T, Tanaka H, Shigenobu K: Enhancement of methoxamine-induced contractile responses of rat ventricular muscle in streptozotocin-induced diabetes is associated with a1A adrenoceptor upregulation. Acta Physiol 2006, 188(3-4):173-183.

47. Novielli NM, Al-Khazraji BK, Medeiros PJ, Goldman D, Jackson DN: Pre-Diabetes Augments Neuropeptide $Y_{1}$ - and $a_{1}$ - Receptor Control of Basal Hindlimb Vascular Tone in Young ZDF Rats. PLOS ONE 2012, 7(10):e46659.

48. Edith-Rodriguez J, Resendiz-Albor AA, Arciniega-Martinez IM, Campos-Rodriguez R, Hong E, Huang F, Villafaña S: Effect of Early Diabetes on the Expression of Alpha-1 Adrenergic Receptors in Aorta and Carotid Arteries of Wistar Kyoto and Spontaneously Hypertensive Rats. Clin Exp Hypertens 2013, 35(6):389-395.

49. Schulingkamp RJ, Aloyo V, Tallarida RJ, Raffa RB: Changes in Aorta Alpha1-Adrenoceptor Number and Affinity during One Year of Streptozotocin-Induced Diabetes in Rats. Pharmacology 2005, 74:23-30.

50. Gando S, Hattori Y, Akaishi Y, Nishihira J, Kanno M: Impaired Contractile Response to Beta Adrenoceptor Stimulation in Diabetic Rat Hearts: Alterations in BetaAdrenoceptors-G Protein-Adenylate Cyclase System and Phospholamban Phosphorylation. J Pharmacol Exp Ther 1997, 282(1):475-484.

51. Lesniewski LA, Donato AJ, Behnke BJ, Woodman CR, Laughlin MH, Ray CA, Delp MD: Decreased NO signaling leads to enhanced vasoconstrictor responsiveness in skeletal muscle arterioles of the ZDF rat prior to overt diabetes and hypertension. Am J Physiol Heart Circ Physiol 2008 294(4):H1840-H1850.

52. Avelar E, Cloward TV, Walker JM, Farney RJ, Strong M, Pendleton RC, Segerson N, Adams TD, Gress RE, Hunt SC, Litwin SE: Left Ventricular Hypertrophy in Severe Obesity: Interactions Among Blood Pressure, Nocturnal Hypoxemia, and Body Mass. Hypertension 2007, 49(1):34-39.

doi:10.1186/s12933-014-0161-4

Cite this article as: Bussey et al:: Increased haemodynamic adrenergic load with isoflurane anaesthesia in type 2 diabetic and obese rats in vivo. Cardiovascular Diabetology 2014 13:161.

\section{Submit your next manuscript to BioMed Central and take full advantage of:}

- Convenient online submission

- Thorough peer review

- No space constraints or color figure charges

- Immediate publication on acceptance

- Inclusion in PubMed, CAS, Scopus and Google Scholar

- Research which is freely available for redistribution

Submit your manuscript at www.biomedcentral.com/submit
C) BioMed Central 